\title{
PARAPLEGIA AFTER ESOPHAGECTOMY: WHO ARE THE PATIENTS AT RISK?
}

Malek G. Massad, MD, Philip E. Donahue, MD, Helene Rubeiz, MD, Allan G. Halline, MD, Arvind Patel, MD,

Teralandur Raghunath, MD, Norman Snow, MD, and Alexander S. Geha, MD, Chicago, Ill

Paraplegia after esophageal resection for carcinoma of the esophagus is rare. A review of the world literature since 1966 showed that only 4 such cases have been reported. ${ }^{1-3}$ We add a fifth case, that of a patient who was referred to our institution for follow-up after resection of adenocarcinoma of the

From the Division of Cardiothoracic Surgery, Department of Surgery, The University of Illinois at Chicago, Chicago, Ill.

Received for publication May 16, 2000; accepted for publication July 11, 2000.

Address for reprints: Malek G. Massad, MD, Division of Cardiothoracic Surgery, University of Illinois at Chicago, $840 \mathrm{~S}$ Wood St, CSB Suite 417 (MC 958), Chicago, IL 60612 (E-mail: mmassad@uic.edu).

J Thorac Cardiovasc Surg 2001;121:386-8

Copyright () 2001 by The American Association for Thoracic Surgery

0022-5223/2001 $\$ 35.00+0 \quad \mathbf{1 2 / 5 4 / 1 1 0 1 7 5}$

doi: $10.1067 / \mathrm{mtc} .2001 .110175$ mid-esophagus. The patient was noted to have paraplegia in the immediate postoperative period, a complication thought to be due to a noncompressive thoracic myelopathy, possibly caused by spinal cord ischemia.

Clinical summary. A 52-year-old man with a history of diabetes mellitus, hypertension, and obesity was admitted to the University of Illinois Hospital 3 months after esophageal resection for carcinoma of the mid-esophagus performed elsewhere. The patient had a history of severe reflux esophagitis complicated by esophageal stricture and Barrett esophagus. He had been treated in the past with several dilatations. Because of symptoms of weight loss and dysphagia to solid food, he underwent an esophagogastroduodenoscopy that showed a sessile ulcerative lesion in the mid-esophagus. Biopsy specimens of that lesion showed a poorly differentiated adenocarcinoma. Subsequently, the patient underwent a subtotal esophagectomy and an intrathoracic esophagogastrostomy performed through a right lateral thoracotomy (Ivor Lewis approach). No perigas- 
Table I. Reported cases of paraplegia after esophagectomy in the world literature between 1966-1999

\begin{tabular}{lccclll}
\hline Author & No. of patients & Age $(y)$, sex & Tumor Location* & Clinical stage ${ }^{\prime}$ & Surgical approach & Spinal cord level \\
\hline Djurberg et al, ${ }^{1}$ 1995 & 1 & $65, \mathrm{M}$ & Distal esophagus & NDA & Right thoracotomy & T7-T9 \\
Boedeker et al, ${ }^{2} 1997$ & 1 & NDA & NDA & III & NDA & T12-L1 \\
Mineo et al, ${ }^{3}$ 1998 & 1 & $72, \mathrm{M}$ & $31 \mathrm{~cm}$ & I & Left thoracotomy & T10-L1 \\
& 1 & $58, \mathrm{M}$ & $27 \mathrm{~cm}$ & I & Transhiatal & T6-T7 \\
Massad et al & 1 & $52, \mathrm{M}$ & $25 \mathrm{~cm}$ & IIA & Right thoracotomy & T9 \\
(present study) & & & & &
\end{tabular}

NDA, No data available.

*Values are given as centimeters from incisors.

†American Joint Commission on Cancer and Union Internationale Contre le Cancer (AJCC/UICC) classification.

tric or paraesophageal lymph nodes appeared to be involved. The patient had an epidural catheter placed by the anesthesiologist before the procedure, reportedly without difficulty, and did not receive excessive amounts of analgesia through the catheter perioperatively. The patient was noted to be paraplegic in the recovery room after his operation. Neurologic examination showed absence of motor function in both lower extremities, with absent deep tendon reflexes and no response to painful stimuli (pin-prick sensation) or to temperature and light touch below the T9 level. These findings were consistent with an acute thoracic myelopathy and spinal shock. Computed tomographic scanning of the thoracic and lumbar spine obtained 24 hours after the operation showed no evidence of any extradural mass or clot, thereby excluding the possibility of spinal cord metastasis or compression by a hematoma caused by the epidural catheter. Magnetic resonance imaging of the spine was performed 3 weeks later. The lower thoracic segment of the cord was slightly widened on magnetic resonance imaging. Sagittal T1 weighted and double-echo axial images, with fat suppression technique and gadolinium contrast enhancement, were obtained and showed a 3- to 4-cm fusiform region of enhancement of the conus medullaris that corresponds to the region of widening of the cord. The findings were suggestive of a spinal cord infarction in the absence of a compressive lesion, a primary neoplasm, or an inflammatory process. Despite continued medical and rehabilitation treatments, the patient's neurologic status remained unchanged, and he died of septic complications 8 months after the esophageal operation.

Discussion. Despite our experience with esophageal resections, we have not encountered this complication before, nor did we encounter it on review of other large-center experiences. $^{4-6}$ A detailed review of the world literature between 1966 and 1999 showed only 4 similar cases of paraplegia occurring after esophageal resection, to which we add this present case (Table I). All 5 cases described occurred among men in the 58- to 72-year age group who were known to have advanced arteriosclerotic disease (3/5 patients) or significant risk factors for arteriosclerosis, such as diabetes mellitus, hypertension, and obesity. The tumor was located in the midesophagus to distal esophagus in all cases, and the level of spinal cord injury was localized somewhere between the T6 and L1 segments of the spinal cord, the thoracolumbar part commonly fed by the great radicular artery of Adamkiewicz. ${ }^{7}$
Mineo and associates ${ }^{3}$ described the condition in a 72-yearold man who underwent esophageal resection and esophagogastroplasty for an early squamous cell carcinoma of the mid-esophagus to lower esophagus through a left thoracotomy. In their case, tumor dissection necessitated the interruption of some of the aortic branches. Twenty-four hours later, the patient had paraplegia with absent reflexes between the T10 and T11 segments and later died. Postmortem examination showed infarction of the spinal cord at the T12 to L1 level. Merlier and Thevenet $^{8}$ described a similar case of injury to the spinal cord after a Nissen fundoplication performed through a left thoracotomy and surmised that the damage was probably related to interruption of branches from the intercostal arteries supplying the spinal cord.

Several disease conditions are known to affect the blood flow to the spinal cord and cause paraplegia, including arteriosclerosis, tumor, infection, disc herniation, aneurysms, trauma, and toxic effects of locally applied analgesics and anesthetic agents. ${ }^{1}$ Additionally, surgical procedures requiring extreme positioning on the operating table may lead to compression of the radicular artery as it passes through an intervertebral foramen narrowed by osteophytes. ${ }^{1}$ Paraplegia resulting from inadequate blood supply through the anterior spinal artery produces a clinical picture known as anterior spinal artery syndrome, which is characterized by loss of motor function with intact or, more commonly, impaired sensory function below the level of injury. The pathophysiology of the ischemic insult is not very clear. However, it may be related to interruption of blood supply to the spinal cord either by ligating some of the spinal arteries coming off the aorta during the procedure or the inadvertent ligation of the artery of Adamkiewicz ${ }^{2}$ or stagnation of blood flow in the spinal cord as a result of prolonged periods of hypotension occurring during the procedure. ${ }^{1}$ It is also thought that mechanical manipulation of the thoracic aorta in patients with pre-existing advanced arteriosclerosis may lead to peeling of arteriosclerotic plaques within the aortic lumen, leading to occlusion of the artery of Adamkiewicz. ${ }^{2}$ Several other factors could contribute to this injury, including hypotension in the intraoperative period, use of vasopressors, and excessive use of epidural analgesia.

In conclusion, spinal cord lesions rarely occur after esophageal resection and are thought to be due to an ischemic insult. It is important to preoperatively identify patients who are at increased risk of compromised blood flow to the spinal 
cord, such as elderly patients with known advanced arteriosclerotic disease or multiple risk factors for arteriosclerosis, to implement preventive measures that may help avoid this dreadful complication.

\section{REFERENCES}

1. Djurberg H, Haddad M, Anterior spinal artery syndrome: paraplegia following segmental ischemic injury to the spinal cord after esophagectomy. Anaesthesia 1995;50:345-8.

2. Boedeker H, Schmidt J, Zirngibl H. Anterior spinal artery syndrome after thoracoabdominal esophageal resection: a rare complication. Chirurgie 1997;68:902-5.

3. Mineo TC, Cristino B, Ambrogi V. Paraplegia after surgery of the thoracic esophagus. J Thorac Cardiovasc Surg 1998;116:653.

4. Orringer MB, Marshall B, Iannettoni MD. Transhiatal esophagectomy: clinical experience and refinements. Ann Surg 1999;230:392-400.

5. Ellis FH Jr, Heatley GJ, Krasna MJ, Williamson WA, Balogh K. Esophagogastrectomy for carcinoma of the esophagus and cardia: a comparison of findings and results after standard resection in three consecutive eight-year intervals with improved staging criteria. J Thorac Cardiovasc Surg 1997;113:836-46.

6. McLarty AJ, Deschamps C, Trastek VF, Allen MS, Pairolero PC, Harmsen WS. Esophageal resection for cancer of the esophagus: long-term function and quality of life. Ann Thorac Surg 1997;63:1568-72.

7. Williams GM, Perler BA, Burdick JF, et al. Angiographic localization of spinal cord blood supply and its relationship to postoperative paraplegia. J Vasc Surg 1991;13:23-33.

8. Merlier M, Thevenet A. Table ronde sur les complications medullaires de la chirurgie du thorax et de l'aorte et de ses branches. Ann Chir Thorac Cardiovasc 1980;34:521-55. 